\title{
Workplace learning and development in tennis coaching
}

\author{
Caio Corrêa Cortela ${ }^{a}$ (D) , Cesar Kist, Hugo Daibert, Alexandre Vinicius Bobato Tozetto ${ }^{b}$ \& \\ Michel Milistetd ${ }^{\mathrm{b}}$ \\ ${ }^{a}$ Paranaense Tennis Federation, Curitiba, Brazil. ${ }^{\mathrm{b}}$ Federal University of Santa Catarina, \\ Florianopolis, Santa Catarina, Brazil.
}

ABSTRACT

Technology is becoming constantly present in coaches' development around the world. Among the core coaching competences, planning, conducting and evaluating are inherent to coaches' daily practice. In this article, we share the results of an online experience for the development of coaching assessment competence.

\author{
Key words: professional \\ development, sport coaching, e- \\ learning. \\ Received: 06 May 2020 \\ Accepted: 12 June 2020 \\ Corresponding author: Caio Corrêa \\ Cortela, Paranaense Tennis \\ Federation, R. Pastor Manoel \\ Virgínio de Souza, 1020 - Capão da \\ Imbuia, Curitiba - PR, 82810-400, \\ Brazil. Email: \\ capacitacao@cbtenis.com.br
}

\section{INTRODUCTION}

Moments of crisis like the ones we are experiencing as a result of the COVID-19 pandemic, can be favourable for significant advances, in a short period of time. This seems to be the scenario of sports coaches, who have been reviewing their professional intervention to meet the new demands and strategies employed in their development. However, in this moment the main source of coaches' learning, which is personal connections with other professionals, is not available (Stoszkowski \& Collins, 2016).

For the Brazilian tennis coaches, the current phase has contributed to a movement of approximation between the professionals and to the engagement in different learning opportunities. The number of coaches at the ITF Academy has grown significantly, taking the country to fourth place in absolute values of registered professionals. The lives, video conferences and thematic meetings, in virtual environments such as Instagram, ZOOM and Google Meet, created a movement never seen before in the country, bringing together well-known actors of Brazilian tennis to debate the national context and present their point of view on topics related to the modality.
In the beginning, this movement was accompanied by an expressive number of spectators who felt "anxious" (FOMO addiction) due to not being able to follow all the actions

published on social networks. Almost three months later, even with the social distance maintained in most of the country, the situation seemed to have changed, with a substantial reduction in these actions and in the participation of coaches. This change or demotivation of professionals reveals the coaches' perception that learning does not occur simply by accumulating information (Trudel et al., 2013). The professional learning process depends on elements such as the possibilities of trying new ideas, implementing them in coaches' work routine and having support to reflect on the results of the applied strategies.

Considering the benefits of the platforms of social interaction, this experience report describes the work done for the development of a competence considered central to coaches', the evaluation of the training session, in a project that aims to provide continuous professional development of coaches within their work context.

THE SCENARIO 
The project takes place at Fly Sports, a reference company in the process of training tennis players in Brazil, with three headquarters in the city of Belo Horizonte. At the beginning of the work, the company had approximately 400 tennis players ( $n=320$ participation and $n=80$ performance) and 18 coaches with $18.7 \pm 12.3$ years of professional experience.

\section{THE PROGRAM}

The objective of this program was to contribute coaches' ongoing learning, based on the workplace learning perspective (Rynne et al., 2010). Previously, the action plan was planned to take place primarily in person, through monthly visits to the company units. With the COVID-19, it was necessary to restructure the strategies, aiming to take advantage of the moment of interruption of activities to advance the work with the coaches, with all the actions being carried out in a virtual environment. Figure 1 presents the summary of the steps completed prior to the evaluation cycle.
The second point of attention identified in the diagnosis phase was the lower self-perception of knowledge and skills related to the evaluation of the training session. Even as they attribute great importance to the evaluation process, tennis coaches demonstrate difficulties in implementing this competence, which is considered fundamental for success in their activity (Cortela et al. 2020a).

In this way, actions were taken to improve the coaches' evaluation capacity. Five thematic meetings were held, with each of these moments being composed of two cycles, shown in Figure 2.

\section{On-site diagnostic phase:}

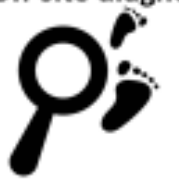

1- On-site visit for

observations:

Participation in the companys

annual meoting to leam about

strategic alignment for the

Diagnostic and planning phase - online:

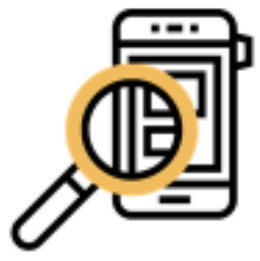

1- Applieation of Googie Forms (Coaches: $n=18$ ) - Quingud et af. (2018) - Cosches knowledge and comoetence questionsire - CKCO - Cortela et al (2000) Scain of Leaming Stustions for Sports Cosches - ESATE

\section{2- Semi-structured interviews: Founding Partinar in = 1 - time: 8321 " Members in $=2$; fime $6900 . \pm 561$ Tectnical Coordinstors in $=4$ - time. $621^{*} \pm 35^{\prime \prime 16}$}

3- Documer

system.

HR and dzctibution in the units.
4- Visirs to the units: - Syzderristic absevafions of work routines.
5. Shutown COVID-19:



2. Thematic Analysis of the Interviows.

- Descrnotve aruglysis of quantiative

instruments

- Triangulstion of data with

syederngecobonnations and

document anstysis.

\section{1st Thematic Cycle online - Establishing the Work Philosophy:}

\begin{abstract}
1st Weeting: Developing the
Work Philosophy

- Reflective Actinty f: Rapposport

Timelive

- Sopport muferia: Synthesis and Artiche

Develagment Cycle: ZOaM par minj.

Reflective Activity 2. Eztsblizhment of

persongl and compavy valver

Sopport Naberist: Videos aboot values

and life abelis.

'Individos' activity feedbuck

Whatsipol
\end{abstract}

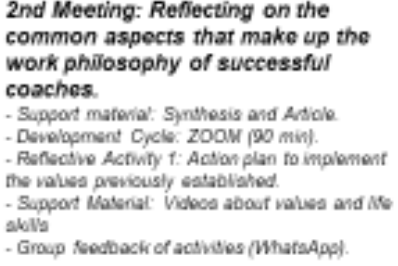

coaches.

- Group Nondeock of activiles (WharaApe).
3. Reflecting on FLY SPORTS Mission, Vision and Values. - Develogment Cycle: ZOOM (111 min).

- Ratlocowe Activiy 1: Acrion plan so suplicisy work on Aubonomy and

Rosilence dining the fraining seasion - Suppert Mafowa: Didactio waseos for

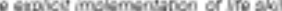
and values.

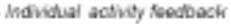
WharaAgel.

\section{Validation of the work proposa (Managers: $n=3$ ). mplcations (Meeting if) Wevtofion with the group fo extsblizh the (Neeting 2) - Algnment and valdation of the intigl vereion of the Action Plan (Meeting 21}

Figure 1: General overview of the steps taken in the program.

The program started in a diagnosis phase through meetings with club stakeholders. As a result of the diagnosis phase, the company's work philosophy, Mission, Vision and Values were reviewed and adjusted. In possession of this information, the first moment of formation of the program addressed the construction of a work philosophy. The coaches were encouraged to make their values explicitly, to identify the points of approach with the company's philosophy and to transform these values into practical actions in their coaching. Developing the competence to evaluate the training session

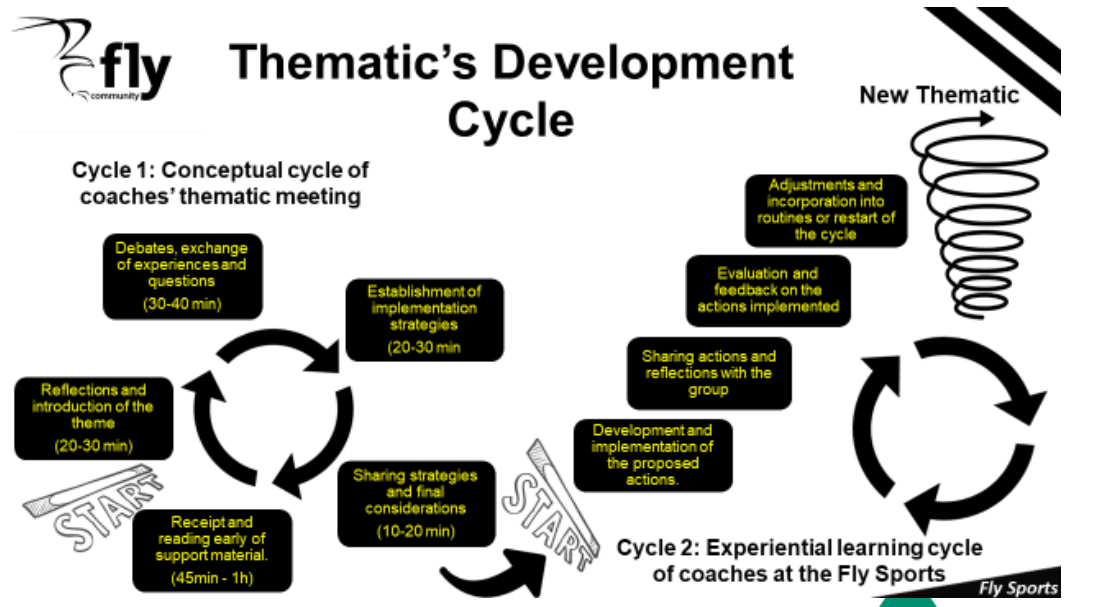

August 2020, 28th Year, Issue 81 
Figure 2: Basic structure of the Theme Development Cycle. The first cycle is intended to deepen the discussions on the targeted competence, combining different learning situations (mediated, non-mediated and internal). This strategy was adopted based on the results and suggestions described by Cortela et al. (2020b) and after the identification of a distinct trend of attribution of importance to the sources of learning by the coaches of the different units, who presented varied profiles of experience and context of performance.

The second cycle aims to provide opportunities for coaches to put into practice, during work routines, the competence in development. The need to experience and have support for reflection is fundamental so that information can be transformed into deeper levels of learning (Trudel et al. 2013).

All actions related to the development of the evaluation competence of the training session took place in a virtual environment. The total meeting time was approximately seven hours. It is noteworthy that four days before each meeting, the coaches received support material (articles, summaries and / or infographics), in order to foster the ability to debate the topic to be addressed.
In parallel to the meetings (Figure 4), a tool was developed for recording and evaluating the training, in line with the literature and the methodology and terminology adopted by the company. In the company's routine, the technical coordinators have to plan the sessions of the week and share them with the coaches, who are responsible for implementing them on the court. However, it was not identified in the process the record of the coaches' feedback regarding the fulfilment of the planned activities / times, nor about the qualitative aspects of the training. This piece of information that is often undervalued by the coaches has pivotal importance for the improvement of the planning, conduction and evaluation process of coaching. The absence of this information makes planning obsolete, since the actions placed on paper may not reflect the work on the court and causing subsequent planning to deviate from the real needs of tennis players (Coelho, 2016).

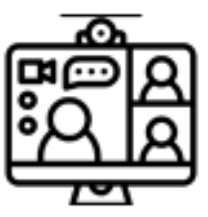

\section{2nd Thematic Cycle online - Evaluating the training session 27/04 to 05/06 \\ Before the meeting $(B)$ and After the meeting (A)}

Introduction to the evaluation of the training session. ( $87 \mathrm{~min})$

B) Reflect: What factors do you consider important for the evaluation of the training session? Mentimeter (A) Register a training session planned for 1 hour to check if the instrument meets FLY's needs: Google forms. (A) Assess the clarity and relevance of the instrument based on the standard form: Geogle Forms.

Developing an instrument to evaluate the Training session - FLY. (100 min)

(A) Record the training sessions performed during the week with comoetition athletes, Google forms.

Points of attention for evaluation of the training session. (94 min)

(B) Evaluate the model class (20 min) avaliable vis YouTube. (B) Register on the FLY Evalustion Registration Form: Google forms.

Evaluating a training session based on Form FLY 1. (99 $\mathrm{min}$ )

(AB) Evaluate the model class $(20 \mathrm{~min})$ wailable via YouTube (AB) Register in the FUY Evaluation Riegistration Form: Google forms.

Evaluating a training session based on Form FLY 2. (91 min)

(A) Evaluate the model class (20 min) avallable via YouTube. (A) Register on the FLY Evaluation Riegistration Form: Google forms. (B) Reflection on the overall results after the evaluations. WhatsApp Group.

\section{Results}

Quantitative assessment: Reflective Card.

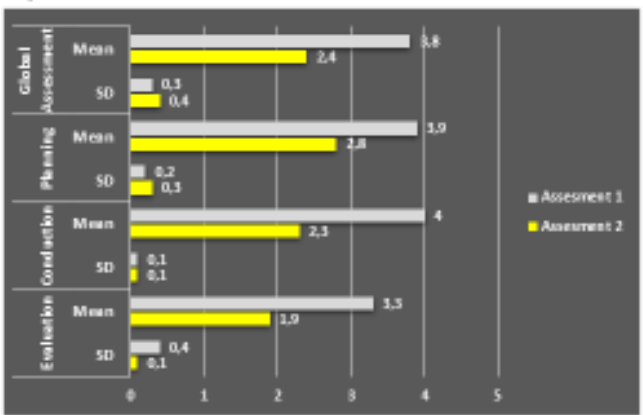

Qualitative assessment: Feedbacks.

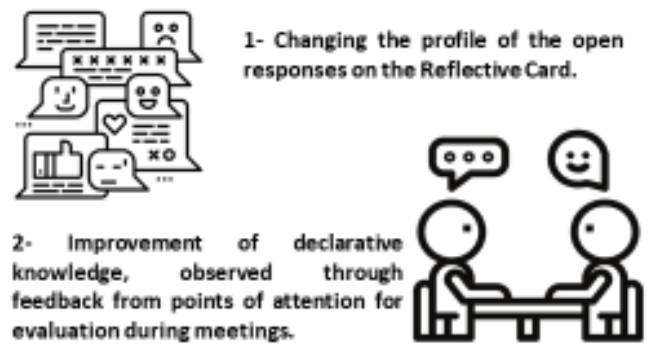

Figure 3: Basic structure of the implemented actions and preliminary results.

After each Conceptual Cycle, coaches were "challenged" to implement practices and reflect on them. The lack of opportunities for face-to-face interaction and real situations on the court, where the assessment could be carried out, was overcome through the use of short video lessons (20 $\mathrm{min}$ ), provided by the Coach Developer, with common situations in the training sessions. 


\section{Construction of the instrument:}

Initial version of the instrument

Precored by the flirst a thor based on Ineraturesnd AY methodologi

Evaluation of Managers and Coordinators

Registraticn of s training session by the project lesders and feedtwok on the instrument and itsaligement with the context

Instrument alignment (Version 2),

Adjustment of the instrument based on feodback from lesders.

Pilot Cosches Application Presentation to cosches and pilot application. Evalustion of the quality of the rument bythe criteria of Clarity, Relewance and methodological alignment of the Feedback Meeting

Meeting with the group of cosches to improve the instrument

Mecting with two technical cocrdinators for feedback and alignment of instrumerts for purticipation and performance.

Instrument alignment (Version 3).

Pilet 2 Application, Coaches

Registration and evaluation of training for groups allowed to return to the courts.

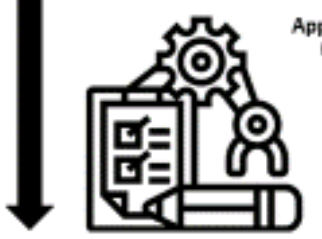

Application Version - Incorporated into the routine

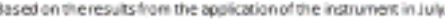

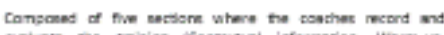

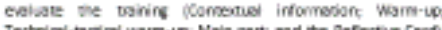

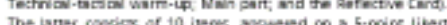
The laner coress of 10 itent, arowered on a 5.poing vient

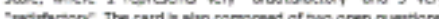

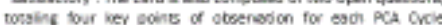
cerpostench

Figure 4: Process of instrument construction.

Before the last two Thematic's Development Cycles the coaches had to evaluate the training sessions through videos. During the meetings they watched the videos again but segmented by sections of analysis. After each block they were able to share their perceptions and were asked by the Coach Developer to reflect and debate key points of the coach's intervention, which were presented in the scene. These meetings ended with the coaches accessing the individual preliminary assessment and the results presented by the general group, and being invited to review their notes made on the Reflective Card.

The preliminary results suggested that the strategies implemented were effective for improving the coaches' assessment capacity (Figure 3). By analysing at least twice of each selected videos and receiving support (support materials and Coach Developer's special help) during the process, the coaches changed their perception of key points related to the quality of the training.

The responses of the Reflective Card (Figure 3) indicated a greater critical capacity of the coaches when evaluating the second video, which presented similar situations to those found in the first. In the same direction, there was greater clarity and a change in the profile of the qualitative training assessment open responses, aimed at identifying the points of attention for the planning of the next sessions, with a focus on the technical aspects of the tennis players who participated of the session (ex: improving control with change of direction; improving the timing; technical aspects of movement), for the didactic-pedagogical aspects of the training and the coach's intervention (present objective at the beginning of the session and end the training by doing the connection with the training objective, greater consistency in the connection between the exercises that were not aligned with each other and with the main objective).

CONCLUSION

The use of technology, through simulated training videos, combined with deliberate reflection, proved to be a viable possibility for the development of the evaluation competence of tennis coaches. Studies using this combination have shown positive results with different coach profiles, indicating an improvement in self-awareness about the training philosophy on professional intervention.

The scenario of COVID-19 brought to the fore the recognition of the importance of the use of technologies for coaches' development, and this is a trend that should be increasingly observed in the daily lives of these professionals. However, it seems urgent to move forward in order to give meaning to the use of this important tool.

If, on the one hand, technological advances allow us to be connected and access an immeasurable amount of data, on the other hand we are challenged that this information has quality and can be accommodated and converted into knowledge.

Thematic chats and meetings are important and can serve as a trigger for learning. However, in order to move to deeper levels and favour the process of accommodating this information as knowledge, other premises must be fulfilled, such as: the recognition of the contextual needs of the coaches as a starting point for learning; engaging in deliberate learning routines for continuous improvement; openness to the new and the possibility of experimentation; and support for the implementation and reflection on new routines.

\section{REFERENCES}

Cortela, C. C., Milistetd, M., Both, J., Galatti, L., Crespo, M., \& Balbinotti, C. A. A. (2020a). Formación permanente y autopercepción de competencia: un estudio con entrenadores de tenis. Pensar en Movimiento: Revista de Ciencias del Ejercicio y la Salud, v. 18, p. e41586, https://doi.org/10.15517/pensarmov.v18i1.41586

Cortela, C. C., Milistetd, M., Both, J., Fuentes, J. P., \& Balbinotti, C. A. A. (2020b). Desenvolvimento profissional de treinadores de tênis: situações e contextos de aprendizagem. Retos v. 38, p. 700-707, https://doi.org/10.47197/retos.v38i38.76760

Rynne, S. B., Mallett, C. J., \& Tinning, R. (2010). Workplace learning of high performance sports coaches. Sport, Education and Society, v. 15, n. 3, p. 315-330, https://doi.org/10.1080/13573322.2010.493312

Stoszkowski, J., \& Collins, D. (2016). Sources, topics and use of knowledge by coaches. Journal of Sports Sciences, 34(9), 794-802, https://doi.org/10.1080/02640414.2015.1072279

Trudel, P, Culver, D, \& Werthner, P. (2013). Looking at coach development from the coach-learner's perspective: considerations for coach development administrators. In: Potrac, P., Gilbert, W., Denison, J. (Eds.). (pp. 375-387). Routledge handbook of sports coaching. Abingdon: Routledge. 
RECOMMENDED ITF TENNIS ACADEMY CONTENT (CLICK BELOW)

\section{ITF Academy}

Copyright (c) 2020 Caio Corrêa Cortela, Cesar Kist, Hugo Daibert, Alexandre Vinicius Bobato Tozetto \& Michel Milistetd

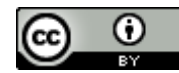

This text is under a Creative Commons BY 4.0 license

You are free to Share - copy and redistribute the material in any medium or format - and Adapt the content - remix, transform, and build upon the material for any purpose, even commercially under the following terms:

Attribution: You must give appropriate credit, provide a link to the license, and indicate if changes were made. You may do so in any reasonable manner, but not in any way that suggests the licensor endorses you or your use.

CCBY4.0license terms summary CCBY4.0license terms 